\title{
Rhodnius barretti, a new species of Triatominae (Hemiptera: Reduviidae) from western Amazonia
}

\author{
Fernando Abad-Franch ${ }^{1,2} /{ }^{+}$, Márcio G Pavan ${ }^{3,4}$, Nicolás Jaramillo-O ${ }^{5}$, Francisco S Palomeque ${ }^{2}$, \\ Carolina Dale $^{6}$, Duverney Chaverra ${ }^{5}$, Fernando A Monteiro ${ }^{3}$
}

\author{
${ }^{1}$ Instituto Leônidas e Maria Deane-Fiocruz, Manaus, AM, Brasil ${ }^{2}$ Centro de Investigación en Enfermedades Infecciosas, \\ Pontificia Universidad Católica del Ecuador, Quito, Ecuador ${ }^{3}$ Laboratório de Epidemiologia e Sistemática Molecular \\ ${ }^{4}$ Laboratório de Biologia Molecular de Insetos ${ }^{6}$ Laboratório Nacional e Internacional de Referência em Taxonomia de Triatomíneos, \\ Instituto Oswaldo Cruz-Fiocruz, Rio de Janeiro, RJ, Brasil ${ }^{5}$ Grupo de Biología y Control de Enfermedades Infecciosas, \\ Instituto de Biología, Universidad de Antioquia, Medellín, Colombia
}

Rhodnius barretti, a new triatomine species, is described based on adult specimens collected in rainforest environments within the Napo ecoregion of western Amazonia (Colombia and Ecuador). R. barretti resembles Rhodnius robustus s.l., but mitochondrial cytochrome $\mathrm{b}$ gene sequences reveal that it is a strongly divergent member of the "robustus lineage", i.e., basal to the clade encompassing Rhodnius nasutus, Rhodnius neglectus, Rhodnius prolixus and five members of the $\mathrm{R}$. robustus species complex. Morphometric analyses also reveal consistent divergence from R. robustus s.l., including head and, as previously shown, wing shape and the length ratios of some anatomical structures. R. barretti occurs, often at high densities, in Attalea butyracea and Oenocarpus bataua palms. It is strikingly aggressive and adults may invade houses flying from peridomestic palms. R. barretti must therefore be regarded as a potential Trypanosoma cruzi vector in the Napo ecoregion, where Chagas disease is endemic.

Key words: Rhodnius barretti sp. nov. - Rhodniini - Amazonia - geometric morphometrics - mitochondrial DNA

The Triatominae are blood-sucking Reduviidae (Hemiptera, Heteroptera) notorious as the vectors of Trypanosoma cruzi, causative agent of Chagas disease. While all of the over 140 currently recognised triatomine species can potentially transmit the parasite among mammals, just a few are epidemiologically relevant vectors of human infection (Lent \& Wygodzinsky 1979, Barrett 1991, Schofield \& Galvão 2009).

The tribe Rhodniini comprises two paraphyletic genera, Rhodnius and Psammolestes (Monteiro et al. 2000, 2002). Most Rhodnius species preferentially breed in palm trees across their native ranges (Barrett 1991, AbadFranch et al. 2009). Flying from palms, adult specimens frequently invade, and sometimes colonise, houses and peridomestic structures (Fitzpatrick et al. 2008, GurgelGonçalves et al. 2008, Justi et al. 2010). Throughout Amazonia and several further Neotropical ecoregions,

doi: 10.1590/0074-0276130434

Financial support: UNDP/UNICEF/World Bank/WHO TDR Special Program (A20441, 970195), CNPq, SVS/MS (Brazil), FIOCRUZ-FAPEAM.

This work benefited from international collaboration through the ECLAT Network.

MGP received scholarship from CNPq and CD from CAPES. FSP current address: Influenza Division, National Center for Immunization and Respiratory Diseases, Centers for Disease Control and Prevention, Atlanta, GA, USA

+ Corresponding author: fernando@amazonia.fiocruz.br

Received 8 September 2013

Accepted 24 October 2013 invasion of houses and other premises by adult Rhodnius spp is probably the main mechanism underlying Chagas disease transmission, either as an endemic infection or in the form of outbreaks linked to food contamination (Grijalva et al. 2003, Aguilar et al. 2007, Valente et al. 2009, Amunárriz et al. 2010, Calzada et al. 2010, Coura \& Junqueira 2012).

While the morphological traits of Rhodnius allow for easy genus-level identification, many species lack clearcut diagnostic characters and remain difficult to identify: a few species are near-sibling and others are in fact species complexes encompassing several cryptic taxa (Lent \& Wygodzinsky 1979, Monteiro et al. 2003, AbadFranch et al. 2009). Currently, the genus comprises 18 named species occurring in Central and South America. Biogeographic and genetic data suggest a northern Palaeo-Amazonian origin of the tribe Rhodniini, which comprises two main lineages: the "pictipes lineage" and the "robustus lineage" (Abad-Franch \& Monteiro 2007, Abad-Franch et al. 2009). Cryptic speciation seems to have occurred along both lineages, including the clades comprising Rhodnius pallescens, Rhodnius robustus-prolixus, and Rhodnius pictipes (Monteiro et al. 2003, Pavan \& Monteiro 2007, Abad-Franch et al. 2009, Gómez-Palacio et al. 2012). On the other hand, phenotypic variation without significant genetic divergence has been recorded in several triatomine species (Schofield et al. 1999, Abad-Franch 2003). When cryptic speciation and phenotypic plasticity both occur within a single genus, it comes as no surprise that taxonomic errors arise: while cryptic taxa are overlooked, some species are formally described based on minor morphological variation. Thus, Rhodnius milesi (Valente et al. 2001) is probably a Rhodnius neglectus variant from 
south-eastern Amazonia, Rhodnius zeledoni (Jurberg et al. 2009) closely resembles Rhodnius domesticus, and Rhodnius montenegrensis (da Rosa et al. 2012) likely represents one of the $R$. robustus lineages of Monteiro et al. (2003). Furthermore, some Rhodnius species, such as Rhodnius dalessandroi, Rhodnius paraensis or Rhodnius amazonicus, have seldom been collected; their ecological-evolutionary characteristics and affiliations remain therefore unclear (Barrett 1991, Abad-Franch et al. 2009, Bérenger et al. 2009).

Integrative taxonomic approaches are particularly useful when the organisms of interest are prone to cryptic speciation, phenotypic plasticity, or both (Dayrat 2005, Bickford et al. 2007). By combining morphological and molecular evidence, such approaches help solve systematic problems that would otherwise remain elusive (Monteiro et al. 2001, Abad-Franch \& Monteiro 2005). In addition, they yield information on characters that can be measured under a variety of circumstances, including morphological traits allowing for rapid identification in the field; doubtful assignments can be resolved later by checking further traits in the laboratory (Monteiro et al. 2001, Gurgel-Gonçalves et al. 2008).

Here, we use an integrative approach, including qualitative and quantitative phenotypic assessments and DNA sequencing, to elucidate the specific status of a Rhodnius population from the Napo ecoregion of western Amazonia (Ecuador and Colombia). Márquez et al. (2011) also studied Napo specimens using morphometric and molecular techniques; their findings suggested that specific status was appropriate for this population. As for the " $R$. robustus-like forms" of Márquez et al. (2011), the Napo specimens we studied were first identified as $R$. robustus; yet, detailed analyses showed them to belong to a new species (Abad-Franch 2003, Abad-Franch \& Monteiro 2005, Abad-Franch et al. 2009), which we name Rhodnius barretti and formally describe in the present paper.

\section{MATERIALS AND METHODS}

Triatomines - We examined Rhodnius specimens from Puerto Asís, Colombia and from Francisco de Orellana and Lago Agrio, Ecuador.

Morphology and morphometrics - A Zeiss Stemi SV11 stereomicroscope was used for the measurement and description of morphological characters. Linear measurements and head capsule landmark coordinates (Fig. 1, Table) were taken from 37 adult $R$. barretti specimens (34 from Colombia and 3 from Ecuador) and 12 R. robustus s.l. (from Colombia, Ecuador, Bolivia, Brazil, French Guiana, Peru, Suriname and Venezuela). Landmark coordinates were recorded using tpsDig 1.18 (Rohlf 1999a). Shape variables were computed using the Generalised Procrustes superimposition algorithm (Rohlf 1996), which derives a least-squares consensus configuration from raw coordinate data. "Partial warps" were then computed as deformations of each structure in relation to the consensus configuration using tpsRelw 1.18 (Rohlf 1999b). Shape variables derived from partial warps were used as input for canonical variate (discrimi- nant) analysis and a plot showing the position of each specimen on the "shape discriminant space" was built with the first two canonical vectors (Fig. 2). Multivariate analyses were conducted using JMP 3.2.6 (SAS Institute, Cary, NC, USA).

Molecular analyses - Samples of four putative $R$. barretti specimens ( 2 from Ecuador and 2 from Colombia), consisting of one or two legs, were placed apiece in a $1.5 \mathrm{~mL}$ microtube, dipped into liquid nitrogen and ground to powder for DNA extraction using a Real Genomics ${ }^{\mathrm{TM}}$ kit. A 663-bp fragment of the mitochondrial (mt) cytochrome $b$ gene (cyt $b$ ) was polymerase chain reaction (PCR)-amplified as described in Monteiro et al. (2003). Amplicons were purified (Hi Yield ${ }^{\mathrm{TM}} \mathrm{Gel} /$ PCR DNA Extraction Kit, Real Genomics ${ }^{\mathrm{TM}}$ ) and both strands were subjected to Sanger sequencing reactions (ABI Prism ${ }^{\circledR}$ BigDye $^{\circledR}$ Terminator v.3.1 Cycle Sequencing Kit, Applied Biosystems) and run on an ABI 3730 sequencer. Consensus sequences were computed and manually aligned as in Monteiro et al. (2003). Homologous sequences from other members of the "robustus lineage" ( $R$. robustus I-V, R. prolixus, $R$. neglectus and Rhodnius nasutus) were added to the alignment; one $R$. pictipes sequence was used to root the phylograms. The Hasegawa, Kishino and Yano model with a proportion of invariable sites was the best-fit model of nucleotide substitution (lowest Akaike Information Criterion value) for phylogenetic reconstruction; it was selected using jModeltest 0.1.1 (Posada 2008).

A Bayesian phylogenetic tree for the complete data set of 13 Rhodnius sequences was inferred in BEAST 1.6.1 (Drummond \& Rambaut 2007) using a "two-partitions" $[(1+2), 3]$ scheme of codon positions. A prior tree was randomly generated and a Yule process of speciation was imposed for all tree reconstructions. Two independent runs were performed for $10^{7}$ generations, with a burn-in of $10^{6}$ generations. Convergence of parameters

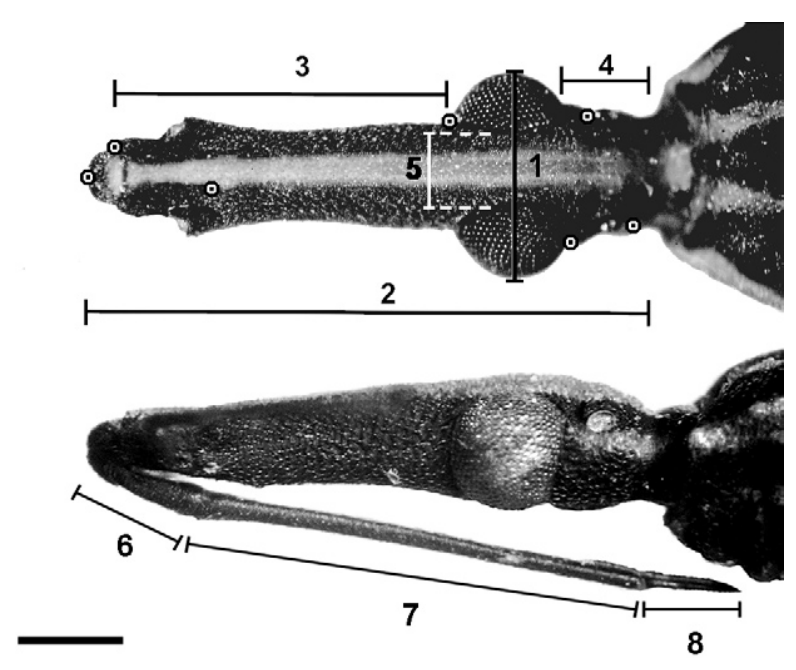

Fig. 1: dorsal (top) and lateral (bottom) views of a Rhodnius barretti head, showing linear measurements (1-8) (Table) and landmarks (target spots) used in morphometric analyses. Bar $=1 \mathrm{~mm}$. 
and proper mixing were confirmed by calculating the effective sample size (ESS) in TRACER 1.5 (Drummond $\&$ Rambaut 2007), excluding the initial 10\% (burn-in) of each run. All considered parameters had ESS $>10^{4}$. Runs were combined using LogCombiner and a maximum credibility tree based on the 10,000 trees (burn-in $=2,000$ ) was generated with a posterior probability limit of 0.6 using Tree Annotator (both part of the BEAST package). Statistical support for clades was assessed by the posterior probability method. The maximum-composite likelihood (M-CL) algorithm available in MEGA 5 (Tamura et al. 2011) was used to estimate a species distance matrix and a heatmap was constructed in the R 2.13 program (Hornik 2011). Distance variance was estimated using 1,000 bootstrap pseudo-replicates.

\section{RESULTS}

\section{$R$. barretti Abad-Franch, Palomeque and Monteiro, sp. nov.}

(Fig. 3)

The possible existence of this new species was first noted by Abad-Franch (2003) and later mentioned by Abad-Franch and Monteiro (2005, 2007), Abad-Franch et al. (2009) and Márquez et al. (2011).

Description - Total length: male 19.10-22.66 mm, female 20.30-24.66 mm. Maximum width of pronotum: male 4.0-4.7 mm, female 4.1-5.0 mm; maximum width of abdomen: male 5.6-6.2 $\mathrm{mm}$, female 5.6-7.2 $\mathrm{mm}$. Overall colour dark brown, slightly paler in some atypical specimens, with yellowish and/or brown-reddish markings and stripes on various parts of the body and appendages (Fig. 3). Head elongated, almost three times as long as wide across the eyes (1:0.36-0.41) and distinctly longer than the pronotum (1:0.72-0.80); granulose both laterally and ventrally; dark brown-blackish, with a dorsal, narrow, light-coloured medial longitudinal stripe extending from clypeus to neck base. Anteocular region approximately four times as long as the postocular region (1:0.23-0.26); eyes large, in lateral view surpassing the lower, but not attaining the upper surface of the head. Ratio eye width-synthlipsis 1:0.9-1.0. Antennae with second article uniformly blackish brown, third article light yellow except dark brown basal fourth; fourth article light-coloured. Ratio of antennal segments 1:8.90-10 .20:4.25-5.30:3.80-4.70. Rostrum dark brown-blackish, with the second segment extending beyond the level of ocelli and almost attaining the neck; ratio of rostral segments 1:3.93-4.00:0.88-0.90.

Pronotum dark brown-blackish, with submedian carinae and lateral margins light yellowish-brown, usually as very narrow stripes but wider in paler specimens (Fig. 3). Posterior lobe with two dark brown-blackish longitudinal stripes between submedian carinae and on each side between submedian carinae and lateral margins; these stripes are separated by slender light bands in typical dark specimens and by lighter, more conspicuous bands in paler specimens. Anterolateral angles of pronotum not prominent. Scutellum dark brown, with 1 +1 light yellowish brown carinae, somewhat widened anteriorly and fused at the base of the light-coloured, narrowly-pointed scutellar process.
Hemelytra dark brown, with veins bordered by conspicuous but narrow light-coloured stripes; space between veins uniformly blackish-brown on the corium, sometimes mixed with lighter diffuse spots on the membrane. Legs with coxae almost entirely blackish to darkreddish-brown and lighter brown trochantera; femora dark reddish brown, tibiae of similar or slightly lighter colour, darker at apex in this latter case. Legs slender, with fore femora about 7.5-8 times as long as wide.

Ventral surface of the abdomen dark brown, speckled with lighter brown in most, but not all specimens; longitudinal medial blackish line, which narrows towards the inter-segment lines and is flanked by $1+1$ submedian, light, wider bands; in each segment, these bands are in turn flanked by $1+1$ sublateral oblique longitudinal marks. Urosternites with a marginal, longitudinal darker band on each side, also bordered by lighter bands. Ventrally, the connexivum is barely visible or completely covered by the urosternites; dorsally, it is light yellowish brown, with each segment almost completely covered by a large brownish-black spot that narrows somewhat, but only slightly in typical dark specimens, towards the posterior end.

Type-locality - Municipality of Puerto Asís $(0.50 \mathrm{~N}$ $76.50 \mathrm{~W}$ ), department of Putumayo, Colombia.

Type data and depository - Holotype male: municipality of Puerto Asís (0.50N 76.50W), department of Putumayo, Colombia, \#3374; Allotype female: municipality of Puerto Asís, department of Putumayo, Colombia, \#3375; Paratypes: four males, municipality of Puerto Asís, department of Putumayo, Colombia, \#3376-3379; four females, municipality of Puerto Asís, department of Putumayo, Colombia, \#3380-3383; three males, municipality of Francisco de Orellana (0.45S 77.00W), Orellana province and municipality of Lago Agrio $(0.08 \mathrm{~S} 76.83 \mathrm{~W})$, Sucumbíos province, Ecuador, \#3384-3386. These specimens are deposited in the Triatominae Collection of the Instituto Oswaldo Cruz, Oswaldo Cruz Foundtion, Rio de Janeiro, Brazil, maintained by the Laboratório Nacional e Internacional de Referência em Taxonomia de Triatomíneos. Five males, municipality of Puerto Asís, department of Putumayo, Colombia, \#CRUA-298, 300, 303, 304, 487; 10 females, municipality of Puerto Asís, department of Putumayo, Colombia, \#CRUA-297, 299, $301,302,342,447-450,484$. These specimens are deposited in the Reduviidae Collection maintained by the Group of Biology and Infectious Disease Control, Universidad de Antioquia, Medellín, Colombia.

Distribution - $R$. barretti is known from the Napo moist forests of western Amazonia, which span the eastern Ecuadorian lowlands $(<1,000 \mathrm{~m}$ altitude) and the adjacent areas of southern Colombia (south of the Caguán River) and northern Peru (north of the middle-lower Marañón River).

Bionomics - R. barretti has been collected in Attalea butyracea and Oenocarpus bataua palm trees in the Ecuadorian Amazon, but may also occur in other palm species (Abad-Franch et al. 2001, Noireau et al. 2002). These palm tree-living colonies are common and can 
reach high densities (Abad-Franch et al. 2010); starved bugs are strikingly aggressive, readily attacking collectors in open daylight (F Abad-Franch \& FS Palomeque, unpublished observations). In contrast, sympatric $R$. robustus are typically found as small colonies (F AbadFranch \& FS Palomeque, unpublished observations). Field observations in Ecuador indicate that $R$. barretti adult specimens can invade houses (FS Palomeque, unpublished observations), probably by flying from heavily infested peridomestic palms.

Etymology - This species is dedicated to Dr Toby Vincent Barrett (National Institute for Amazonian Research, Brazil), in all likelihood the world's top authority on Amazonian triatomine ecology.

Morphometrics - Linear measurements and ratios are presented in the Table. Discriminant analysis of shape shows how specimens designated as $R$. barretti are distinct from $R$. robustus s.l. specimens from a wide geographical range (Fig. 2). The three Ecuadorian R. bar-

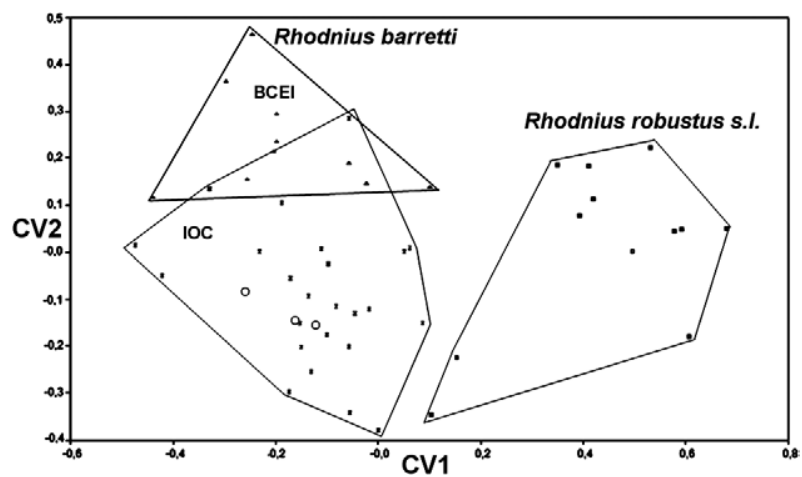

Fig. 2: geometric morphometrics results: factorial map built with the first two canonical vectors (CV) showing $100 \%$ head shape discrimination between $R$. barretti sp. nov. (Colombia and Ecuador) and $R$. robustus s.l. (Bolivia, Brazil, Colombia, Ecuador and French Guiana). $R$. barretti are deposited at the Group of Biology and Infectious Disease Control (BCEI) (Universidad de Antioquia, Medellín, Colombia) and Oswaldo Cruz Institute (IOC) (Rio de Janeiro, Brazil) collections. Ecuadorian specimens are marked as open circles.

TABLE

Anatomical structure metrics in adult Rhodnius barretti sp. nov. and Rhodnius robustus s.l.

\begin{tabular}{|c|c|c|c|c|c|}
\hline \multirow[b]{2}{*}{ Metric } & \multirow[b]{2}{*}{ Description } & \multicolumn{2}{|c|}{$\begin{array}{l}\text { R. barretti } \\
\text { sp. nov. }\end{array}$} & \multicolumn{2}{|c|}{ R. robustus s.l. } \\
\hline & & Male & Female & Male & Female \\
\hline \multirow[t]{11}{*}{ Measurements (mm) } & Total length & $19.1-22.7$ & 20.3-24.7 & $20.0-23.5^{a}$ & $23.0-26.0^{a}$ \\
\hline & Maximum width of pronotum & $4.00-4.70$ & $4.10-5.00$ & $4.50-5.00^{a}$ & $5.00-6.00^{a}$ \\
\hline & Maximum width of abdomen & $5.70-6.00$ & $5.60-7.20$ & $6.00-7.00^{a}$ & $6.00-7.50^{a}$ \\
\hline & Outer (maximum) distance across eyes ( $\# 1$ in Fig. 1 ) & $1.60-1.87$ & $1.60-1.93$ & NR & NR \\
\hline & Synthlipsis (\#5 in Fig. 1) & $0.47-0.61$ & $0.56-0.70$ & $0.46-0.52^{b}$ & $0.52-0.57^{b}$ \\
\hline & Anteocular distance (\#3 in Fig. 1) & $2.50-3.05$ & $2.50-3.30$ & $2.52-2.67^{b}$ & $2.66-2.83^{b}$ \\
\hline & Postocular distance (\#4 in Fig. 1) & $0.65-0.80$ & $0.55-0.85$ & $0.65-0.72^{b}$ & $0.68-0.72^{b}$ \\
\hline & Total length of head (\#2 in Fig. 1) & $4.10-5.00$ & $4.00-5.25$ & $3.97-4.24^{b}$ & $4.17-4.44^{b}$ \\
\hline & Length of first rostral segment (\#6 in Fig. 1) & $0.80-1.00$ & $0.96-1.08$ & $0.70-0.75^{b}$ & $0.75-0.81^{b}$ \\
\hline & Length of second rostral segment ( $\# 7$ in Fig. 1) & $3.50-4.00$ & $3.30-4.20$ & $2.99-3.14^{b}$ & $3.08-3.36^{b}$ \\
\hline & Length of third rostral segment (\#8 in Fig. 1) & $0.78-1.00$ & $0.80-0.91$ & $0.87-0.93^{b}$ & $0.87-0.96^{b}$ \\
\hline \multirow[t]{13}{*}{ Ratios } & Total length:head length & $1: 0.21-0.22$ & $1: 0.20-0.21$ & $1: 0.18-0.20^{c}$ & $1: 0.17-0.18^{c}$ \\
\hline & Total length:pronotum width & $1: 0.21$ & $1: 0.20$ & $1: 0.21-0.23^{a}$ & $1: 0.22-0.23^{a}$ \\
\hline & Total length:abdomen width & $1: 0.27-0.30$ & $1: 0.28-0.29$ & $1: 0.30^{a}$ & $1: 0.26-0.29^{a}$ \\
\hline & Abdomen width:pronotum width & $1: 0.70-0.78$ & $1: 0.69-0.73$ & $1: 0.71-0.75^{a}$ & $1: 0.80-0.83^{a}$ \\
\hline & Head length:head width & $1: 0.36-0.41$ & $1: 0.40^{a}$ & & \\
\hline & Head length:pronotum length & $1: 0.72-0.80$ & $1: 0.70-0.80^{c}$ & & \\
\hline & Eye width:synthlipsis & $1: 0.90-1.00$ & $1: 0.75-1.00^{a}$ & & \\
\hline & Anteocular region:postocular region & $1: 0.23-0.26$ & $1: 0.25^{a}$ & & \\
\hline & First:second antennal segments & $1: 8.90-10.2$ & $1: 7.60-10.2^{a}$ & & \\
\hline & First:third antennal segments & $1: 4.25-5.30$ & $1: 5.40-6.30^{a}$ & & \\
\hline & First:fourth antennal segments & $1: 3.80-4.70$ & $1: 3.40-4.40^{a}$ & & \\
\hline & First:second rostral segments & $1: 3.93-4.00$ & $1: 4.10-4.40^{a}$ & & \\
\hline & First:third rostral segments & $1: 0.88-0.90$ & $1: 0.90-1.00^{a}$ & & \\
\hline
\end{tabular}

$a$ : after Lent and Wygodzinsky (1979); $b$ : mean \pm two standard errors (SE), with values taken from Harry (1994); $c$ : with head length taken from Harry (1994); NR: not reported. Note that some measurements are given as ranges and some as the mean \pm two SE and are therefore not directly comparable. 


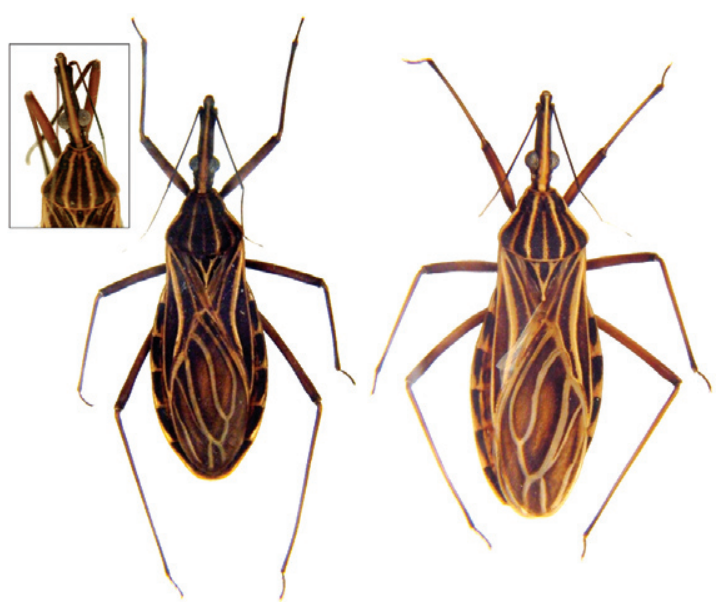

Fig. 3: Rhodnius barretti (left) and sympatric Rhodnius robustus s.l. (right) from north-eastern Ecuador: general aspect of adult specimens in dorsal view. The inset shows the head and pronotum of an atypical, paler form of $R$. barretti.

retti paratypes are clearly nested within the Colombian type material; in addition, this type group overlaps with further specimens from Colombia.

Molecular analysis - The analysis of 13 sequences of Rhodnius for the cyt $b$ gene fragments $(663 \mathrm{bp})$ revealed 201 variable sites, 31 (15.4\%) of which were autapomorphies of $R$. barretti. Three haplotypes were iso- lated from $R$. barretti specimens (GenBank accessions JX273159-JX273162); Colombian bugs shared the same cyt $b$ haplotype, which closely resembled the other two, present in Ecuador. The finding of three haplotypes in a sample of four bugs (mean distance $=0.3 \%$; variance $=0.1 \%$ ) is suggestive of high levels of genetic diversity. $R$. barretti cyt $b$ sequences are unmistakably different from those of other "robustus lineage" members. Such deep divergence is shown in the phylogram presented in Fig. 4; all $R$. barretti specimens cluster together in a $100 \%$-supported clade that is basal to the rest of "robustus lineage" species, including $R$. nasutus and $R$. neglectus. Pairwise cyt $b$ sequence divergence between $R$. barretti and the other Rhodnius species, computed via $\mathrm{M}-\mathrm{CL}$, was very large, ranging from 7.4-10.7\% (darker colours in the heatmap of Fig. 4). These values are larger than those between the four members of the $R$. robustus cryptic species complex and $R$. nasutus or between $R$. robustus I-V and $R$. neglectus. The pairwise sequence divergence between Ecuadorian $R$. barretti and sympatric, field-collected $R$. robustus is $7.5 \%$. Overall, the genetic distance between $R$. robustus and $R$. barretti is $8.7 \%$ (variance $=2 \%$; range, $7.4-9.7 \%$ ). This is strong evidence that $R$. barretti represents a distinct entity within the "robustus lineage".

Taxonomic discussion - Phenotype-based differentiation of $R$. barretti from $R$. robustus, the most closely related species found in sympatry, is difficult. However, sympatric Ecuadorian bona fide $R$. robustus (genotype

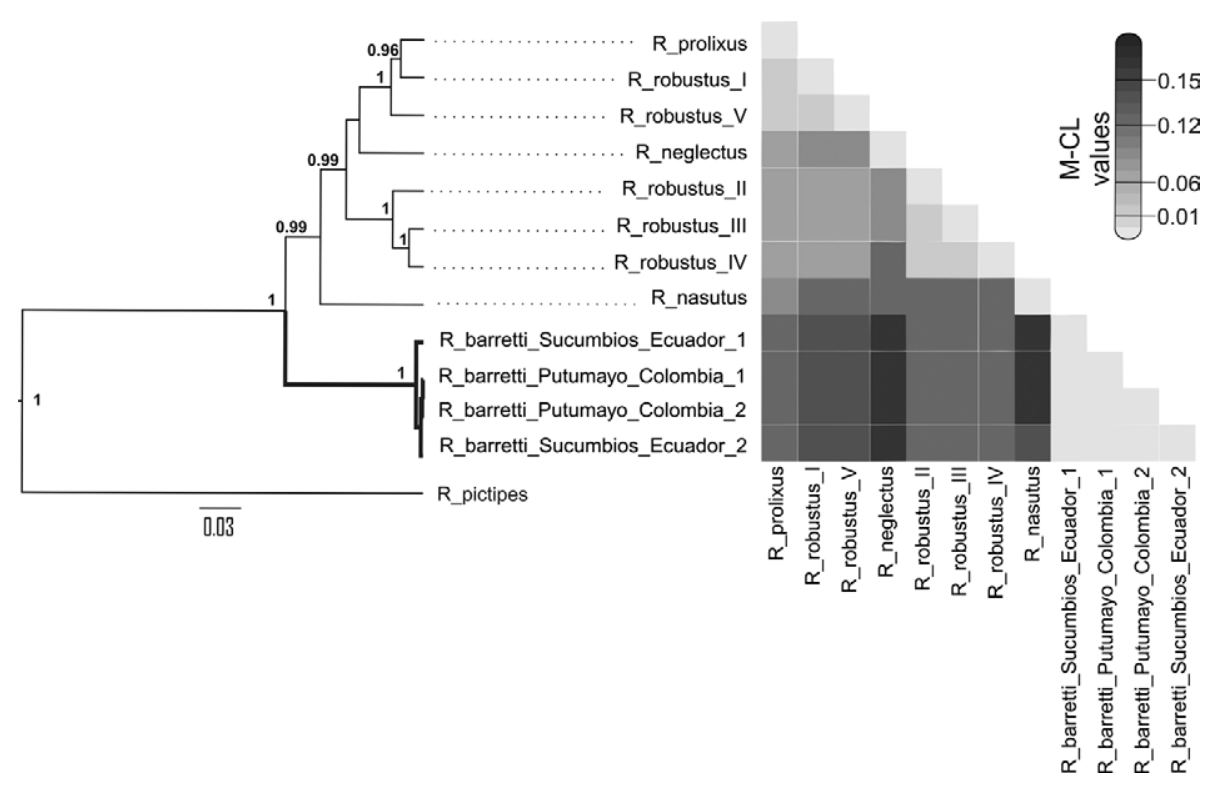

Fig. 4: bayesian consensus tree of 13663 bp cyt $b$ Rhodnius sequences and a heatmap illustrating genetic distance values. Posterior probabilities $>0.95$ are shown for key nodes. Squares in the heatmap illustrate pairwise genetic distance values between sequences, with darker colours representing larger distances (see scale bar). Collection sites and GenBank accessions are: Rhodnius prolixus - Portuguesa, Venezuela, EF011723; Rhodnius robustus I - Trujillo, Venezuela, AF421340; R. robustus II - Napo, Ecuador, AF421341; R. robustus III - Pará (PA), Brazil, AF421342; R. robustus IV - PA, Brazil, AF421342; R. robustus V - Novo Airão, Amazonas (AM), Brazil, JX273158; Rhodnius nasutus - Ceará, Brazil, JX273155; Rhodnius neglectus - Tocantins, Brazil, JX273156; Rhodnius pictipes - AM, Brazil; Rhodnius barretti - Lago Agrio, Sucumbíos, Ecuador (1), JX273159; R. barretti - Lago Agrio, Sucumbíos, Ecuador (2), JX273160; R. barretti - Puerto Asís, Putumayo, Colombia (1 and 2), JX273161 and JX273162. 
II) are conspicuously larger and lighter-coloured (Fig. 4), which should provide a means for field identification by well-trained local entomologists. In addition, the length ratios of several anatomical structures appear to be consistently different from those typically reported for $R$. robustus s.l. (Table). In particular, $R$. barretti heads seem to be longer relative to total body length (with the head accounting for $\sim 20-22 \%$ of total length) than those of $R$. robustus s.l. ( $17-20 \%)$. The third antennal segment appears to be relatively shorter in $R$. barretti (up to 5.3 times as long as the first segment, vs. up to 5.6 in $R$. robustus s.l.); similarly, the second rostral segment is up to 4.0 times as long as the first one in $R$. barretti, vs. up to 4.4 times in $R$. robustus s.l. Finally, the scutellar process is narrowly pointed in $R$. barretti, but stout/rounded in sympatric $R$. robustus (Fig. 4). Although these differences will need to be confirmed with further samples, dubious assignations can be resolved, as shown above and in Márquez et al. (2011), using morphometrics and/ or DNA analysis.

\section{DISCUSSION}

We described $R$. barretti on the basis of an integrative assessment including mtDNA sequencing, morphometrics and qualitative phenotype traits (Abad-Franch \& Monteiro 2005, Schofield \& Galvão 2009). As for the rest of species within the "robustus lineage", $R$. barretti is hard to distinguish from its closest relatives based only on phenotype (Lent \& Wygodzinsky 1979). Still, $R$. robustus genotype II, the only member of the lineage recorded to date in the Napo ecoregion (Abad-Franch et al. 2009), can be distinguished from $R$. barretti by its overall larger size and lighter colour (Fig. 4); it was this difference, in fact, that led one of us to suspect that a distinct taxon might co-occur with $R$. robustus in northeastern Ecuador (Abad-Franch 2003). In addition, the length ratios of some anatomic structures and the apex of the scutellar process appear to be consistently different from those of $R$. robustus s.l. Although we have so far systematically compared only a small sample, $R$. barretti nymphs also seem to differ from those of sympatric $R$. robustus populations. The former are overall dark brown-reddish with strikingly black markings on the thorax and wing pads; the head is very dark except for a slender, median dorsal stripe and the legs are brownreddish with little difference between tibiae and femora. $R$. robustus nymphs are of much lighter overall colour, with brown markings on a yellowish background; their tibiae are usually visibly lighter than the femora (Lent \& Wygodzinsky 1979).

Morphometric analyses can help delineate species boundaries among nearly-cryptic triatomine taxa and are useful for solving taxonomic doubts when adult specimens are involved (Gurgel-Gonçalves et al. 2008). However, and despite consistent phenotype-based evidence, including wing shape differentiation reported by Márquez et al. (2011), it was the results of mtDNA sequence analysis that gave us confidence to conclude that the atypical Napo population belongs to a new species (Márquez et al. 2011). MtDNA sequencing provides insight on the taxonomic status and phylogenetic relation- ships of problem specimens (Abad-Franch \& Monteiro 2005, Justi et al. 2010) and allows for the development of PCR-based species-identification assays (Pavan \& Monteiro 2007, Pavan et al. 2013). While mtDNA sequencing results might be difficult to interpret when reciprocally monophyletic sister clades are separated by low levels $(<$ $4 \%$ ) of sequence divergence (Wiemers \& Fiedler 2007), this was not the case with $R$. barretti, whose divergence from its closest relatives is $>8.7 \%$. According to the cyt $b$ strict molecular clock proposed by Pfeiler et al. (2006) for triatomines, both lineages have probably been evolving independently for about four-nine million years. Márquez et al. (2011) also reported cyt $b$ distances (Kimura 2-parameter) $\geq 10 \%$; inter-species comparisons show that the smallest cyt $b$ distance within the genus Rhodnius (a $4.3 \%$ distance) is that between the phenotypically and ecologically well-differentiated Rhodnius brethesi and Rhodnius stali (FA Monteiro \& MG Pavan, unpublished observations). Márquez et al. (2011) showed, in addition, that one $R$. barretti nuclear 28S rRNA D2 variable region sequence was different from those of other Rhodnius species and genotypes available in GenBank.

We finally note that there could remain some doubts as to whether the Napo population could in fact be $R$. dalessandroi Carcavallo and Barreto 1976. This littleknown species, collected from Oenocarpus palms in the Amazon-Orinoco transition, was excluded from the classic monograph by Lent and Wygodzinsky (1979) and there is no DNA sequence available. Yet, comparison with $R$. dalessandroi descriptions (Carcavallo \& Barreto 1976, Martínez 1984) clearly suggests that $R$. barretti and $R$. dalessandroi are distinct entities. Morphological differences include head/neck and urotergite colouration and hemelytron:abdomen, antenna article and rostrum segment length ratios (Carcavallo \& Barreto 1976, Martínez 1984). These species, in addition, occupy sharply different ecoregions (Abad-Franch et al. 2009).

In conclusion, the results we report here show how an integrative systematic appraisal can help uncover apparently cryptic diversity even within relatively wellstudied taxonomic groups. A hitherto undescribed species of Rhodnius was discovered in the rainforest of the Napo ecoregion - one of the major biodiversity hotspots on Earth (Olson \& Dinerstein 1998, Gaston 2010). This sub-region of Amazonia has also been the focus of detailed surveys on Chagas disease epidemiology over the last two decades (Amunárriz et al. 1991, 2010, Chico et al. 1997, Aguilar et al. 1999, Grijalva et al. 2003, Guevara et al. 2013). All of them converge towards a coherent set of conclusions: (i) that the infection is endemic in the region, with about $2-4 \%$ seropositivity among local residents, (ii) that $T$. cruzi transmission to humans has been continuous over the last decades and is currently active and (iii) that such transmission is maintained by adventitious adult triatomines that invade, but do not colonise, human dwellings. Within the genus Rhodnius, $R$. pictipes and $R$. robustus were up to now blamed for this scenario (Abad-Franch et al. 2001, Noireau et al. 2002); our data suggest that $R$. barretti might also be involved. In addition, a study of the biology and bionomics of Ecuadorian R. barretti specimens, at the time identi- 
fied as $R$. robustus (Palomeque et al. 2003), showed that, under laboratory conditions and fed on mouse blood, $R$. barretti (i) can produce two generations per year, with a mean egg-to-adult time of $128 \pm 7$ days, (ii) require about $290 \mathrm{mg}$ of blood to complete development and (iii) often defaecate (especially older nymphs and adults) during or a few minutes after feeding. These bionomic traits, comparable to those of $R$. prolixus, suggest that $R$. barretti may be an efficient vector of T. cruzi (Palomeque et al. 2003). Our preliminary observations suggest high rates of natural T. cruzi infection among bugs collected in Ecuador (FSP, unpublished observations). $R$. barretti is therefore a new candidate vector species, and its biological and behavioural characteristics suggest that it may play a significant role in Chagas disease epidemiology in the Napo ecoregion.

\section{ACKNOWLEDGEMENTS}

To MA Miles, M Aguilar and MJ Grijalva, for continuous support, SA Valente and MM Lima, for providing R. neglectus and $R$. nasutus specimens, A Gonçalves da Silva, for useful remarks, to Cléber Galvão, for his insightful comments and suggestions. This paper is dedicated to the memory of Alexandre Afranio Peixoto, whose inspiring research on speciation in insect disease vectors deeply influences much of our own work.

\section{REFERENCES}

Abad-Franch F 2003. The ecology and genetics of Chagas disease vectors in Ecuador, with emphasis on Rhodnius ecuadoriensis (Triatominae), PhD Thesis, London School of Hygiene and Tropical Medicine, University of London, London, 411 pp.

Abad-Franch F, Ferraz G, Campos C, Palomeque FS, Grijalva MJ, Aguilar HM, Miles MA 2010. Modeling disease vector occurrence when detection is imperfect: infestation of Amazonian palm trees by triatomine bugs at three spatial scales. PLoS Negl Trop Dis 4: e620.

Abad-Franch F, Monteiro FA 2005. Molecular research and the control of Chagas disease vectors. An Acad Bras Cienc 77: 437-454.

Abad-Franch F, Monteiro FA 2007. Biogeography and evolution of Amazonian triatomines (Heteroptera: Reduviidae): implications for Chagas disease surveillance in humid forest ecoregions. Mem Inst Oswaldo Cruz 102 (Suppl. I): 57-69.

Abad-Franch F, Monteiro FA, Jaramillo N, Gurgel-Gonçalves R, Dias FBS, Diotauiti L 2009. Ecology, evolution and the long-term surveillance of vector-borne Chagas disease: a multi-scale appraisal of the tribe Rhodniini (Triatominae). Acta Trop 110: 159-177.

Abad-Franch F, Paucar CA, Carpio CC, Cuba Cuba CA, Aguilar VHM, Miles MA 2001. Biogeography of Triatominae (Hemiptera: Reduviidae) in Ecuador: implications for the design of control strategies. Mem Inst Oswaldo Cruz 96: 611-620.

Aguilar HM, Abad-Franch F, Dias JCP, Junqueira ACV, Coura JR 2007. Chagas disease in the Amazon Region. Mem Inst Oswaldo Cruz 102 (Suppl. I): 47-55.

Aguilar VHM, Abad-Franch F, Racines VJ, Paucar CA 1999. Epidemiology of Chagas disease in Ecuador. A brief review. Mem Inst Oswaldo Cruz 94 (Suppl. I): 387-393.

Amunárriz M, Chico ME, Guderian RH 1991. Chagas disease in Ecuador: a sylvatic focus in the Amazon Region. J Trop Med Hyg 94: $145-149$.

Amunárriz M, Quito S, Tandazo V, López M 2010. Seroprevalencia de la enfermedad de Chagas en el cantón Aguarico, Amazonía Ecuatoriana. Rev Panam Salud Publica 28: 25-29.
Barrett TV 1991. Advances in triatomine bug ecology in relation to Chagas disease. In KH Harris (org.), Advances in disease vector research, Vol. 8, Springer-Verlag, New York, p. 143-176.

Bérenger J-M, Pluot-Sigwalt D, Pagès F, Blanchet D, Aznar C 2009. The Triatominae species of French Guiana (Heteroptera: Reduviidae). Mem Inst Oswaldo Cruz 104: 1111-1116.

Bickford D, Lohman DJ, Sodhi NS, Ng PKL, Meier R, Winker K, Ingram KK, Das I 2007. Cryptic species as a window on diversity and conservation. Trends Ecol Evol 22: 148-155.

Calzada JE, Pineda V, Garisto JD, Samudio F, Santamaría AM, Saldaña A 2010. Human trypanosomiasis in the eastern region of the Panama province: new endemic areas for Chagas disease. $\mathrm{Am}$ J Trop Med Hyg 82: 580-582.

Carcavallo R, Barreto P 1976. Una nueva especie de Rhodnius Stål (Hemiptera, Reduviidae, Triatominae) de Colombia. Bol Dir Malariol Saneam Amb 16: 176-183.

Chico HM, Sandoval C, Guevara EA, Calvopiña HM, Cooper PJ, Reed SG, Guderian RH 1997. Chagas disease in Ecuador: evidence for disease transmission in an indigenous population in the Amazon Region. Mem Inst Oswaldo Cruz 92: 317-320.

Coura JR, Junqueira ACV 2012. Risks of endemicity, morbidity and perspectives regarding the control of Chagas disease in the Amazon Region. Mem Inst Oswaldo Cruz 107: 145-154.

da Rosa JA, Rocha CS, Gardim S, Pinto MC, Mendonça VJ, Ferreira Filho JCR, de Carvalho EOC, Camargo LMA, de Oliveira J, Nascimento JD, Cilense M, Almeida CE 2012. Description of Rhodnius montenegrensis sp. nov. (Hemiptera: Reduviidae: Triatominae) from the state of Rondonia, Brazil. Zootaxa 3478: 62-76.

Dayrat B 2005. Towards integrative taxonomy. Biol J Linn Soc Lond 85: 407-415.

Drummond AJ, Rambaut A 2007. BEAST: bayesian evolutionary analysis by sampling trees. BMC Evol Biol 7: 214.

Fitzpatrick S, Feliciangeli MD, Sánchez-Martín M, Monteiro FA, Miles MA 2008. Molecular genetics reveal that silvatic Rhodnius prolixus do colonise rural houses. PLoS Negl Trop Dis 2: e210.

Gaston KJ 2010. Biodiversity. In NS Sodhi, PR Ehrlich (eds.), Conservation biology for all, Oxford University Press, Oxford, p. 27-42.

Gómez-Palacio A, Jaramillo-O N, Caro-Riaño H, Diaz S, Monteiro FA, Pérez R, Panzera F, Triana O 2012. Morphometric and molecular evidence of intraspecific biogeographical differentiation of Rhodnius pallescens (Hemiptera: Reduviidae: Rhodniini) from Colombia and Panama. Infect Genet Evol 12: 1975-1983.

Grijalva MJ, Escalante L, Paredes RA, Costales JA, Padilla A, Rowland EC, Aguilar HM, Racines J 2003. Seroprevalence and risk factors for Trypanosoma cruzi infection in the Amazon Region of Ecuador. Am J Trop Med Hyg 69: 380-385.

Guevara AG, Atherton RD, Wauters MA, Vicuña Y, Nelson M, Prado J, Kato H, Calvopiña MH, Hashiguchi Y 2013. Seroepidemiological study of Chagas disease in the southern Amazon Region of Ecuador. Trop Med Health 41: 21-25.

Gurgel-Gonçalves R, Abad-Franch F, Ferreira JBC, Santana DB, Cuba CA 2008. Is Rhodnius prolixus (Triatominae) invading houses in central Brazil? Acta Trop 107: 90-98.

Harry M 1994. Morphometric variability in the Chagas disease vector Rhodnius prolixus. Jpn J Genet 69: 233-250.

Hornik K 2011. The R FAQ. Available from: CRAN.R-project.org/ doc/FAQ/.

Jurberg J, Rocha DS, Galvão C 2009. Rhodnius zeledoni sp. nov. afim de Rhodnius paraensis Sherlock, Guitton \& Miles, 1977 (Hemiptera, Reduviidae, Triatominae). Biota Neotrop 9: 123-128. 
Justi SA, Noireau F, Cortez MR, Monteiro FA 2010. Infestation of peridomestic Attalea phalerata palms by Rhodnius stali, a vector of Trypanosoma cruzi in the Alto Beni, Bolivia. Trop Med Int Health 15: 727-732.

Lent H, Wygodzinsky P 1979. Revision of the Triatominae (Hemiptera, Reduviidae) and their significance as vectors of Chagas disease. Bull Am Mus Nat Hist 163: 125-520.

Márquez E, Jaramillo-O N, Gómez-Palacio A, Dujardin JP 2011. Morphometric and molecular differentiation of a Rhodnius robustuslike form from $R$. robustus Larrousse, 1927 and R. prolixus Stål, 1859 (Hemiptera, Reduviidae). Acta Trop 120: 103-109.

Martínez A 1984. Caracterización taxionómica de Rhodnius dalessandroi Carcavallo \& Barreto, 1976 (Hemiptera, Reduviidae, Triatominae). Chagas 1: 29-31.

Monteiro FA, Barrett TV, Fitzpatrick S, Cordon-Rosales C, Feliciangeli D, Beard CB 2003. Molecular phylogeography of the Amazonian Chagas disease vectors Rhodnius prolixus and R. robustus. Mol Ecol 12: 997-1006.

Monteiro FA, Escalante AA, Beard CB 2001. Molecular tools and triatomine systematics: a public health perspective. Trends Parasitol 17: 344-347.

Monteiro FA, Lazoski C, Noireau F, Solé-Cava AM 2002. Allozyme relationships among ten species of Rhodniini, showing paraphyly of Rhodnius including Psammolestes. Med Vet Entomol 16: 83-90.

Monteiro FA, Wesson DM, Dotson EM, Schofield CJ, Beard CB 2000. Phylogeny and molecular taxonomy of the Rhodniini derived from mitochondrial and nuclear DNA sequences. Am J Trop Med Hyg 62: 460-465.

Noireau F, Abad-Franch F, Valente SAS, Dias-Lima A, Lopes CM, Cunha V, Valente VC, Palomeque FS, de Carvalho-Pinto CJ, Sherlock I, Aguilar M, Steindel M, Grisard EC, Jurberg J 2002. Trapping Triatominae in silvatic habitats. Mem Inst Oswaldo Cruz 97: 61-63.

Olson D, Dinerstein E 1998. The Global 200: a representation approach to conserving the Earth's most biologically valuable ecoregions. Conserv Biol 12: 502-515.

Palomeque FS, Abad-Franch F, Grijalva MJ 2003. Notas sobre la biología y bionomía de Rhodnius robustus Larrouse, 1927 (Hemiptera: Reduviidae: Triatominae). Rev Pontif Univ Cat Ecuador 71: 49-60.

Pavan MG, Mesquita RD, Lawrence GG, Lazoski C, Dotson EM, Abubucker S, Mitreva M, Randall-Maher J, Monteiro FA 2013. A nuclear single-nucleotide polymorphism (SNP) potentially useful for the separation of Rhodnius prolixus from members of the
Rhodnius robustus cryptic species complex (Hemiptera: Reduviidae). Infect Genet Evol 14: 426-433.

Pavan MG, Monteiro FA 2007. A multiplex PCR assay that separates Rhodnius prolixus from members of the Rhodnius robustus cryptic species complex (Hemiptera: Reduviidae). Trop Med Int Health 12: 751-758.

Pfeiler E, Bitler BG, Ramsey JM, Palacios-Cardiel C, Markow TA 2006. Genetic variation, population structure and phylogenetic relationships of Triatoma rubida and T. recurva (Hemiptera: Reduviidae: Triatominae) from the Sonoran desert, insect vectors of the Chagas disease parasite Trypanosoma cruzi. Mol Phylogenet Evol 41: 209-221.

Posada D 2008. jModelTest: phylogenetic model averaging. Mol Biol Evol 25: 1253-1256.

Rohlf FJ 1996. Morphometric spaces, shape components and the effects of linear transformations. In LF Marcus, M Corti, A Loy, GJP Naylor, D Slice (eds.), Advances in morphometrics, Plenum, New York, p. 117-129.

Rohlf FJ 1999a. tpsDig, version 1.18. Available from: life.bio.sunysb. $\mathrm{edu} / \mathrm{morph} /$.

Rohlf FJ 1999b. tpsRelw, version 1.18. Available from: life.bio.sunysb. edu/morph/.

Schofield CJ, Diotaiuti L, Dujardin JP 1999. The process of domestication in Triatominae. Mem Inst Oswaldo Cruz 94 (Suppl. I): 375-378.

Schofield CJ, Galvão C 2009. Classification, evolution and species groups within the Triatominae. Acta Trop 110: 88-100.

Tamura K, Peterson D, Peterson N, Stecher G, Nei M, Kumar S 2011. MEGA5: molecular evolutionary genetics analysis using maximum likelihood, evolutionary distance and maximum parsimony methods. Mol Biol Evol 28: 2731-2739.

Valente SAS, Valente VC, Pinto AYN, Barbosa CMJ, dos Santos MP, Miranda CO, Cuervo P, Fernandes O 2009. Analysis of an acute Chagas disease outbreak in the Brazilian Amazon: human cases, triatomines, reservoir mammals and parasites. Trans $R$ Soc Trop Med Hyg 103: 291-297.

Valente VC, Valente SAS, Carcavallo RU, Rocha DS, Galvão C, Jurberg J 2001. Considerações sobre uma nova espécie do gênero Rhodnius Stål, do estado do Pará, Brasil (Hemiptera, Reduviidae, Triatominae). Entomol Vectores 8: 65-80.

Wiemers M, Fiedler K 2007. Does the DNA barcoding gap exist? - a case study in blue butterflies (Lepidoptera: Lycaenidae). Front Zool 4: 8 . 